\title{
Surgical treatment of scoliosis: a review of techniques currently applied
}

\author{
Toru Maruyama*1 and Katsushi Takeshita ${ }^{2}$
}

Address: ${ }^{1}$ Department of Orthopaedic Surgery, Saitama Medical Center, Saitama Medical University, Saitama, Japan and ${ }^{2}$ Department of Orthopaedic Surgery, Faculty of Medicine, The University of Tokyo, Tokyo, Japan

Email: Toru Maruyama* - tmaruyama17@yahoo.co.jp; Katsushi Takeshita - takeshita-ort@h.u-tokyo.ac.jp

* Corresponding author

Published: 18 April 2008

Scoliosis 2008, 3:6 doi:10.1186/1748-7|61-3-6

This article is available from: http://www.scoliosisjournal.com/content/3/1/6

This is an Open Access article distributed under the terms of the Creative Commons Attribution License (http://creativecommons.org/licenses/by/2.0), which permits unrestricted use, distribution, and reproduction in any medium, provided the original work is properly cited.

\begin{abstract}
In this review, basic knowledge and recent innovation of surgical treatment for scoliosis will be described. Surgical treatment for scoliosis is indicated, in general, for the curve exceeding 45 or 50 degrees by the Cobb's method on the ground that:

I) Curves larger than 50 degrees progress even after skeletal maturity.

2) Curves of greater magnitude cause loss of pulmonary function, and much larger curves cause respiratory failure.

3) Larger the curve progress, more difficult to treat with surgery.

Posterior fusion with instrumentation has been a standard of the surgical treatment for scoliosis. In modern instrumentation systems, more anchors are used to connect the rod and the spine, resulting in better correction and less frequent implant failures. Segmental pedicle screw constructs or hybrid constructs using pedicle screws, hooks, and wires are the trend of today.

Anterior instrumentation surgery had been a choice of treatment for the thoracolumbar and lumbar scoliosis because better correction can be obtained with shorter fusion levels. Recently, superiority of anterior surgery for the thoracolumbar and lumbar scoliosis has been lost. Initial enthusiasm for anterior instrumentation for the thoracic curve using video assisted thoracoscopic surgery technique has faded out.

Various attempts are being made with use of fusionless surgery. To control growth, epiphysiodesis on the convex side of the deformity with or without instrumentation is a technique to provide gradual progressive correction and to arrest the deterioration of the curves. To avoid fusion for skeletally immature children with spinal cord injury or myelodysplasia, vertebral wedge ostetomies are performed for the treatment of progressive paralytic scoliosis. For right thoracic curve with idiopathic scoliosis, multiple vertebral wedge osteotomies without fusion are performed. To provide correction and maintain it during the growing years while allowing spinal growth for early onset scoliosis, technique of instrumentation without fusion or with limited fusion using dual rod instrumentation has been developed. To increase the volume of the thorax in thoracic insufficiency syndrome associated with fused ribs and congenital scoliosis, vertical expandable prosthetic titanium ribs has been developed.
\end{abstract}




\section{Review}

Considering that not all the scoliosis patients can be treated successfully with conservative treatment and severe and/or progressive scoliosis often need surgery, even the specialists of conservative treatment should have knowledge about surgical treatment. In this review, basic knowledge and recent innovation of surgical treatment for scoliosis will be described. Because relatively little data are obtained regarding outcomes in the long-term or clinical outcomes such as patients' satisfaction, the particular techniques will be discussed mainly based on the radiological outcomes in the middle-term, sometimes shortterm follow-up.

\section{Indication of surgery}

Surgical treatment for scoliosis is indicated, in general, for the curve exceeding 45 or 50 degrees by the Cobb's method on the ground that:

1) Curves larger than 50 degrees progress even after skeletal maturity. Thoracic curves with magnitude between 50 and 75 degrees at skeletal maturity (Risser IV or V) progressed of an average of 29.4 degrees over the 40.5 years follow-up period [1]. Curves larger than 55 degrees at skeletal maturity (partial or total fusion of the completed iliac apophyses) progressed of more than 0.5 degrees per year [2]. Thoracic curves with an average Cobb angle of 60.5 dgrees progressed to 84.5 degrees over the 50 years follow-up period [3].

2) Curves of greater magnitude cause loss of pulmonary function, and much larger curves cause respiratory failure. In patients with curves between 60 and 100 degrees, total lung capacity was $68 \%$ of predicted normal values [4]. Nearly half of the patients with thoracic curve larger than $80^{\circ}$ degrees had shortness of breath at the average age of 42 years [5]. Vital capacity below $45 \%$ predicted and a Cobb angle greater than 110 degrees were risk factors to develop respiratory failure and earlier death [6].

3) Larger the curve progress, more difficult to treat with surgery: more surgical anchors may be necessary, longer operation time, more blood loss, higher surgical complication rate may be expected.

Sometimes patient's motivation to straighten her/his spine by surgery should be respected, especially for the patient with gray zone curve, Cobb angle of 40 to 45 degrees.

Surgical treatment for scoliosis can be divided into fusion surgery and fusionless surgery.

\section{Fusion surgery}

\section{Posterior instrumentation}

Posterior fusion with instrumentation has been a standard of the surgical treatment for scoliosis since first introduced by Paul Harrington [7]. In his system, correction force was applied with distraction along the concavity of the curve. In the second generation instrumentation system developed by Cotrel and Dubousset [8], correction was attempted by the rod-rotation maneuver. In modern instrumentation systems, more anchors are used to connect the rod and the spine, resulting in better correction and less frequent implant failures [9]. Segmental pedicle screw constructs (Fig. 1, 2) or hybrid constructs using pedicle screws, hooks, and wires (Fig. 3, 4) are the trend of today.

A segmental pedicle screw concept was first introduced by Suk [10]. He reported that the idiopathic thoracic curves of 51 degrees in average were corrected to 16 degrees (69\% correction) with a minimum 5-year follow-up. Although $1.5 \%$ of the screws inserted in the thoracic level were malpositioned, they did not cause neurologic complications or adversely affect the long-term results. Asher et al. [11] reported on $63 \%$ correction with a minimum 5year follow-up using hybrid constructs with hooks, apical sublaminar wires, and pedicle screws. In 2005, Cheng et al. [12] compared apical sublaminar wires with pedicle screws. No difference was found regarding initial correction $(67.4 \%$ vs. $68.1 \%)$, loss of correction $(4.6 \%$ vs. $5.1 \%$ ), operating time (350 minutes vs. 357 minutes), satisfaction of the patients, but intraoperative blood loss was more with wires $(1791 \mathrm{ml}$ vs. $824 \mathrm{ml})$ and instrumenta-

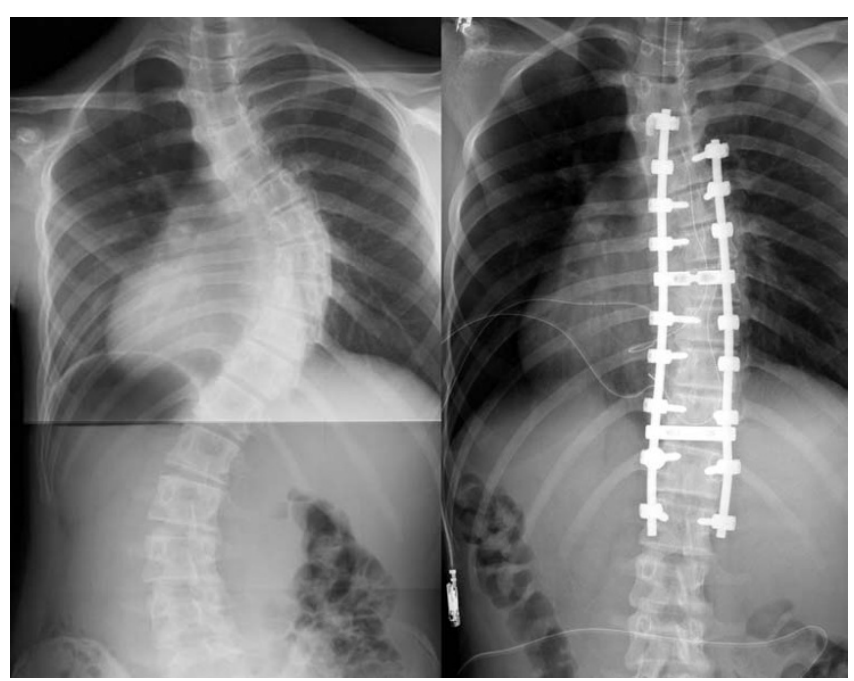

Figure I

Segmental pedicle screw constructs. Right thoracic curve between the T5 and TII was corrected from 68 to 25 degrees. 


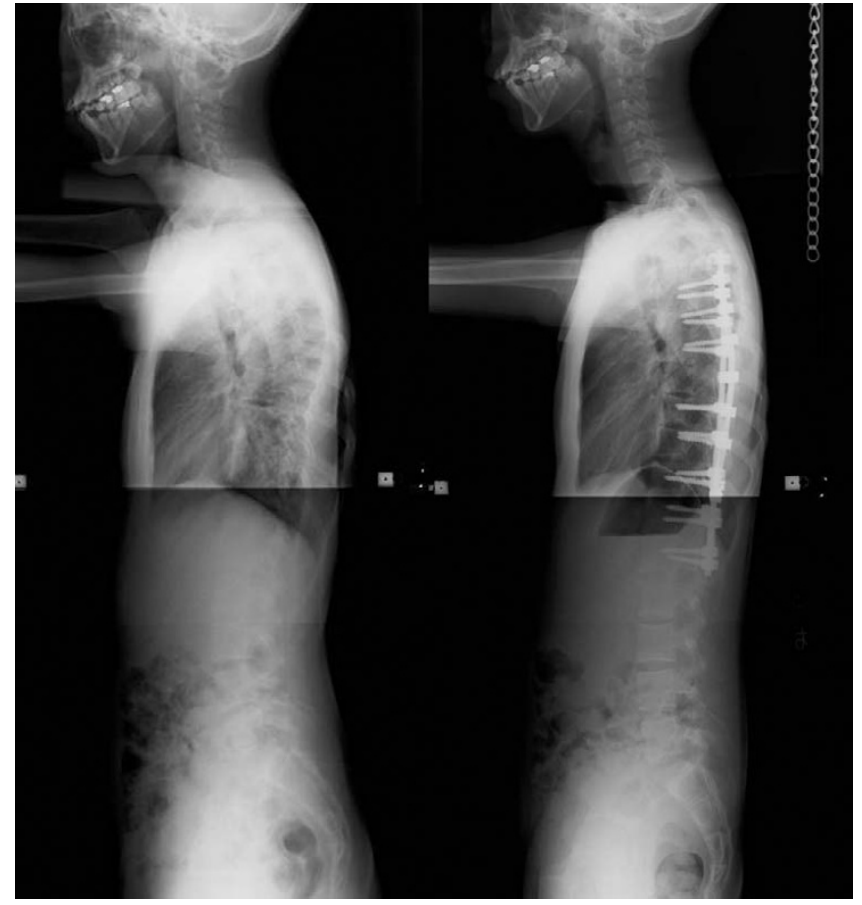

Figure 2

Segmental pedicle screw constructs. Lateral radiographs before and after surgery.

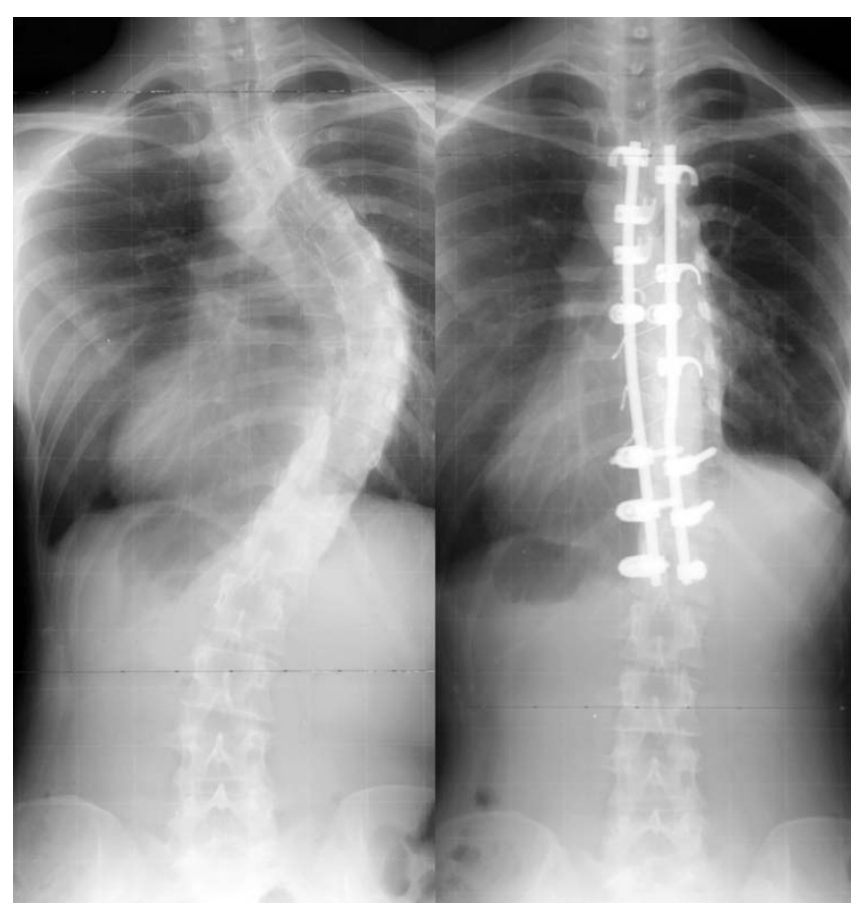

Figure 3

Hybrid constructs using pedicle screws, hooks, and wires. Right thoracic curve between the T5 and TII was corrected from 70 to 23 degrees.

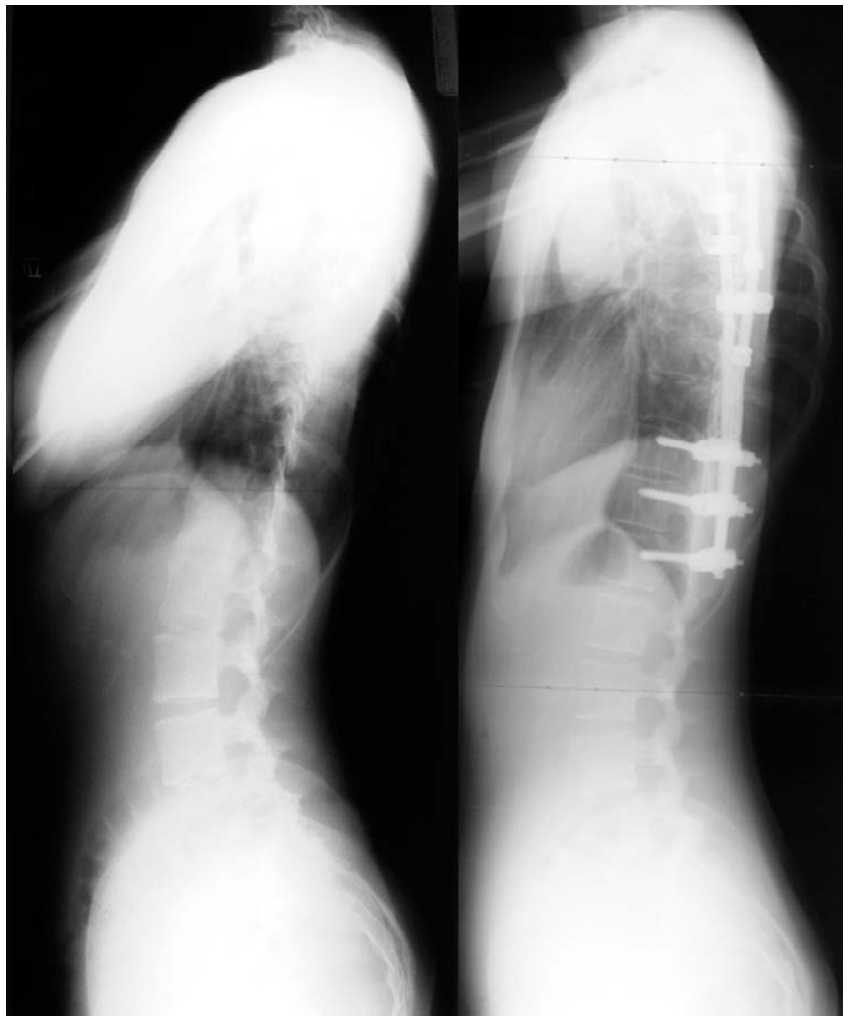

Figure 4

Hybrid constructs using pedicle screws, hooks, and wires. Lateral radiographs before and after surgery.

tion cost was higher with screws (8341 USD vs. 13462 USD). Another concern with segmental pedicle screw constructs is that vigorous correction of a major curve is an overcorrection relative to the flexibility of the upper compensatory curve [13]. Generally, an extent of fusion level is determined with the flexibility of the curves demonstrated on the radiographs taken in supine side bending, fulcrum side bending, traction, or push-prone position [14-16]. With segmental pedicle screw technique, to avoid the postoperative shoulder imbalance, frequently fusion has to be extended to the upper thoracic vertebrae, which is not included in the fusion with other techniques.

\section{Anterior instrumentation}

Anterior instrumentation surgery (Figure 5, 6) had been a choice of treatment for the thoracolumbar and lumbar scoliosis because better correction can be obtained with shorter fusion levels. Moreover, anterior instrumentation for the thoracic curve using video assisted thoracoscopic surgery technique had been developed [17]. Initial enthusiasm for this surgery in expectation of decreased postoperative pain or patients' satisfaction with less operative scar has faded out because the thoracic aorta is at risk if screw penetrated the cortex on the opposite side $[18,19]$, and disruption of the chest cage during the surgical treat- 


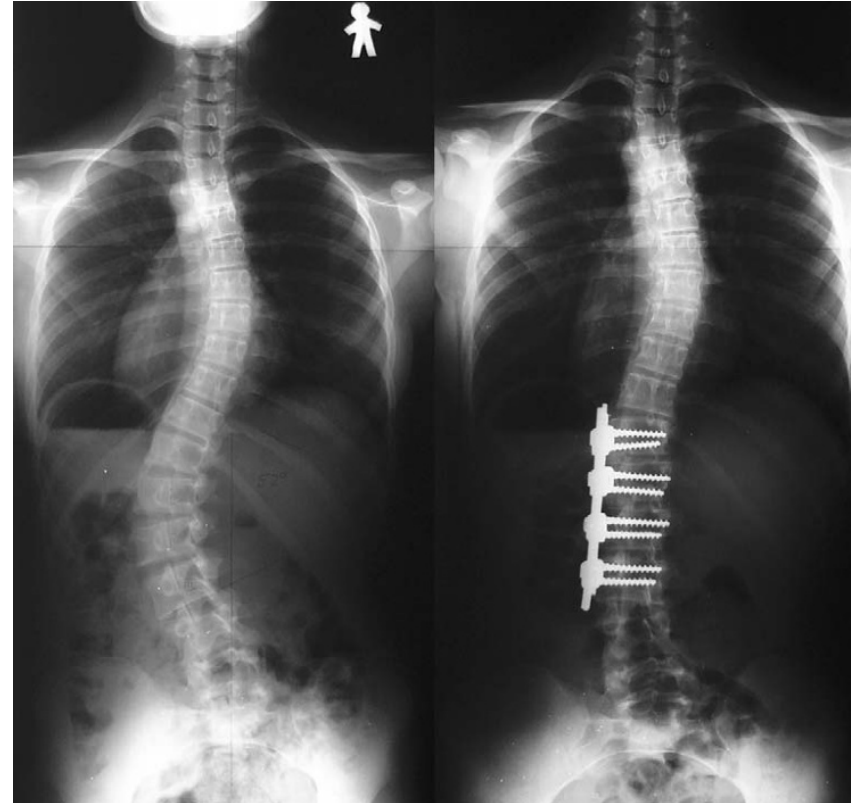

Figure 5

Anterior instrumentation surgery. Left thoracolumbar curve between the TII and L4 was corrected from 52 to 19 degrees (By courtesy of Dr. Tomasz Kotwicki).

ment affects the pulmonary function after surgery [20]. Thoracic curve can be treated successfully with posterior instrumentation surgery without affecting pulmonary function. In 2005, Potter et al. [21] compared anterior spinal fusion and posterior spinal fusion for the treatment of single thoracic curve, and concluded that posterior fusion group demonstrated greater curve correction (62\% versus $52 \%$ ) and greater rib hump correction (51\% versus $26 \%$ ). Recently, superiority of anterior surgery for the thoracolumbar and lumbar scoliosis has been lost. In 2007, Hee et al. [22] compared segmental pedicle screw instrumentation and anterior instrumentation in adolescent idiopathic thoracolumbar and lumbar scoliosis. They reported that the coronal correction at a minimum 2-year follow-up was compatible ( $68 \%$ vs. $67 \%$ ), but length of surgery was significantly shorter (189 minutes vs. 272 minutes) and length of hospital stay was shorter (6.2 days vs. 8 days) in the posterior segmental pedicle screw group.

\section{Fusionless surgery}

Various attempts are being made with use of fusionless surgery to control growth, to avoid fusion, to delay the timing of the definitive fusion surgery, or to increase the volume of the thorax.

\section{To control growth}

Epiphysiodesis on the convex side of the deformity with or without instrumentation is a technique to provide gradual progressive correction and to arrest the deteriora-

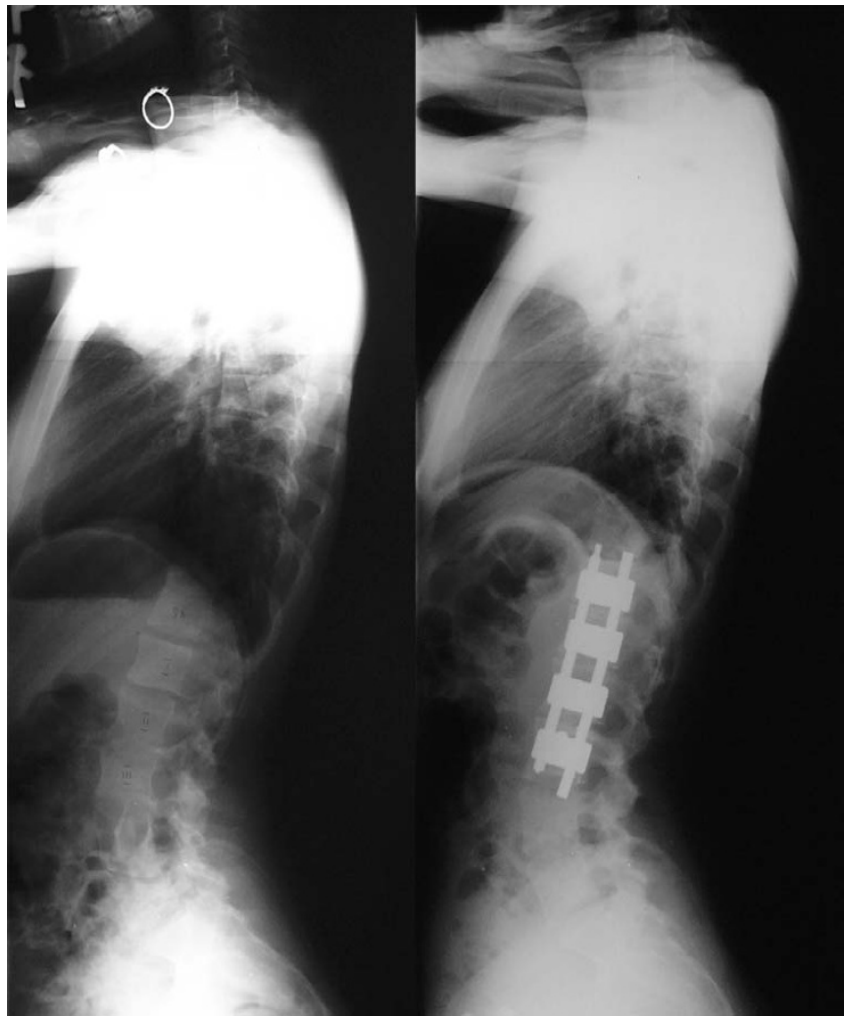

Figure 6

Anterior instrumentation surgery. Lateral radiographs before and after surgery (By courtesy of Dr. Tomasz Kotwicki).

tion of the curves. Marks et al. [23] found anterior and posterior growth arrest alone not effective to prevent progression of deformity in infantile scoliosis. To the contrary, Betz et al. [24] showed that stapling the anterior vertebral spinal growth plates could control growth of the curve with adolescent idiopathic scoliosis. By using newly designed biocompatible shape memory metal alloy staples, 6 of 10 patients with average curve magnitude of 35 degrees were stabilized during more than 1-year follow-up period. To avoid the overtreatment for relatively small, non-progressive curve with this technique, definite and solid criteria for hallmarking a curve as progressive should be established first.

\section{To avoid fusion}

By fusion surgery, segmental motion of the vertebral column is eliminated. To avoid fusion for patients with paralysis, for whom maintaining spinal flexibility and mobility is more desirable, fusionless, vertebral wedge ostetomies are developed for the treatment of progressive paralytic scoliosis of skeletally immature children with spinal cord injury or myelodysplasia [25]. A specially designed implant system is used to assist with correction and maintenance of alignment. Twelve weeks following 


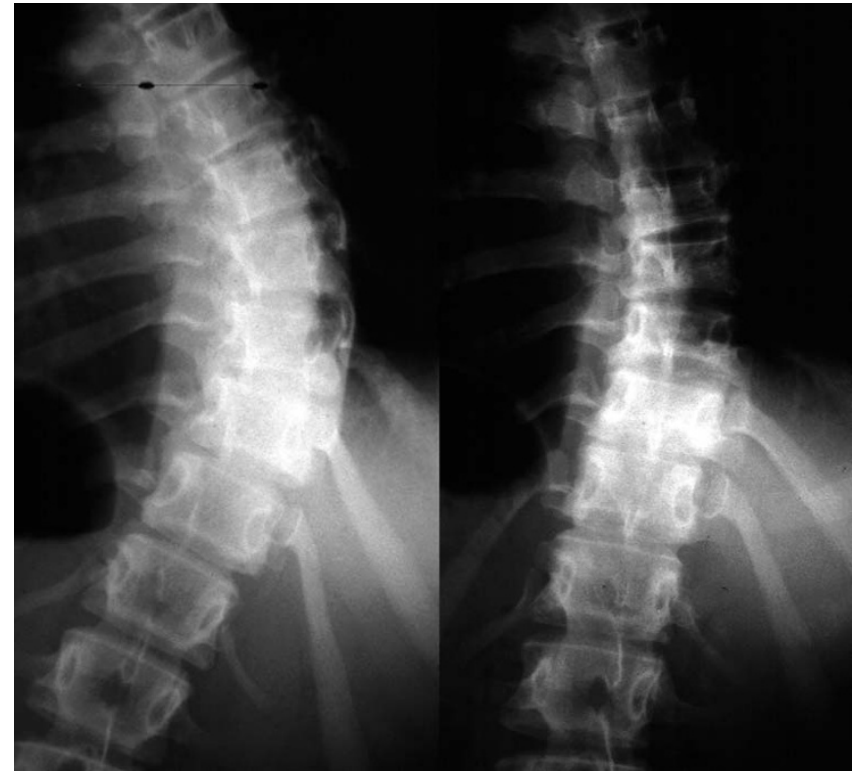

Figure 7

Multiple vertebral wedge osteotomy. Right thoracic curve between the T5 and TI 2 corrected from 56 to 26 degrees.

the initial surgery, a second surgery is necessary to remove parts of the implants. This technique may be used for idiopathic scoliosis in future.

For right thoracic curve with idiopathic scoliosis, multiple vertebral wedge osteotomies without fusion (Fig. 7, 8) are performed [26]. Twenty patients were treated with osteotomies on the averaged 3.6 periapical vertebrae and followed-up for 8.9 years on an average. There were no neurologic complications. For four patients with Risser 0 or I, average curve magnitude was 74.8 degrees before surgery and 67.5 degrees at the latest follow-up (correction rate was $9.8 \%$ ), whereas, for 16 patients with Risser IV or $\mathrm{V}$, that was 61.3 degrees before surgery and 43.3 degrees at the latest follow-up (correction rate was 29.4\%).

\section{To delay the timing of fusion}

Fusion surgery in very young age results in the short trunk relative to the extremities. It also affects the development of the lung. To provide correction and maintain it during the growing years while allowing spinal growth for early onset scoliosis, technique of instrumentation without fusion or with limited fusion using Harrington rod, Cotrel-Dubousset rod, or Luque rod had been developed $[27,28]$. Recently, Akbarnia et al. [29] developed the technique using Isola dual rod instrumentation. Upper and lower foundations are made bilaterally using hooks or pedicle screws as anchoring devices. Each foundation is connected to a rod, and the rods are connected by a tandem connector, which is placed at the thoracolumbar

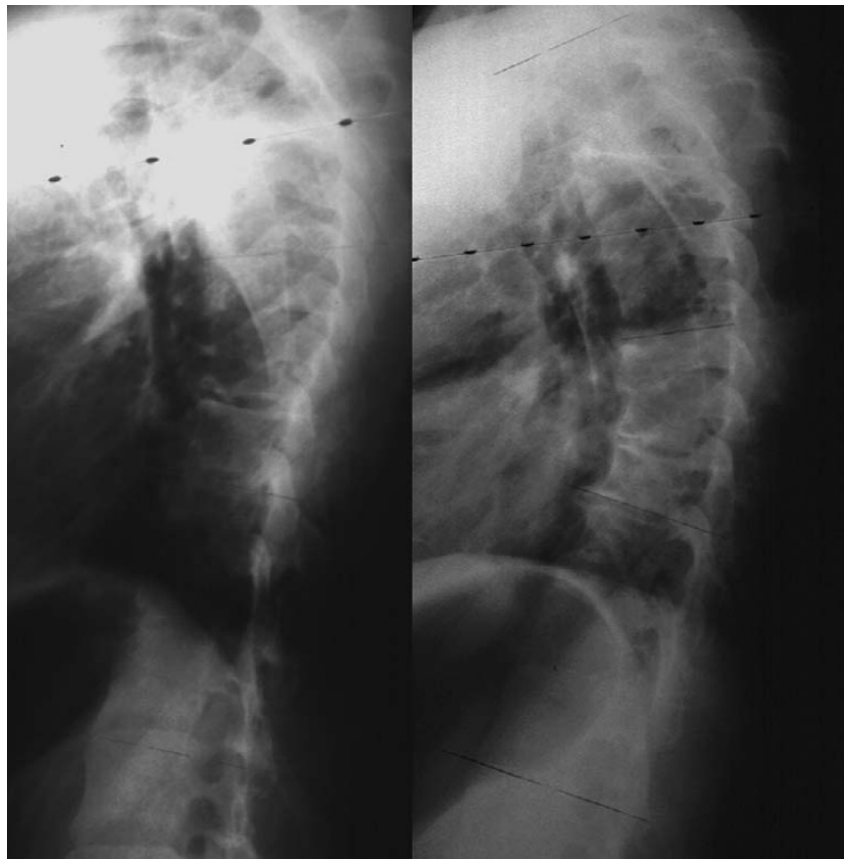

Figure 8

Multiple vertebral wedge osteotomy. Lateral radiographs before and after surgery.

junction on each side. Lengthening is performed usually every 6 months by distraction inside the tandem connector or between the rod and the tandem connector. Once maximum spinal growth is accomplished, definitive final arthrodesis with instrumentation is performed. Between 1993 and 2001, 23 patients with various etiologies underwent this treatment at an average age of 5.4 years. The averaged curve magnitude was 82 degrees before surgery, 38 degrees after the initial surgery, and 36 degrees after 6.6 times of lengthening procedures. The length of thoracic and lumbar spine increased by $5 \mathrm{~cm}$ at the initial surgery and $4.7 \mathrm{~cm}$ in addition during the lengthening period.

To increase the volume of the thorax

To treat thoracic insufficiency syndrome associated with fused ribs and congenital scoliosis, vertical expandable prosthetic titanium ribs (VEPTR) has been developed [30]. After opening-wedge thoracostomy, the acute correction is stabilized by the device. The device is extended from the cephalad rib to the caudal rib, to the lumbar spine, or to the posterior iliac crest. Following the initial implantation, the devices are expanded at scheduled intervals of four to six months. Twenty-seven patients underwent surgery at the average age of 3.2 years and were followed-up for 5.7 years. Vital capacity significantly increased; moreover, scoliosis deformity was indirectly corrected from 74 to 49 degrees at the last follow-up. 


\section{Conclusion}

We described the indication of surgical treatment for scoliosis, results of the innovative surgical techniques, in terms of, posterior fusion with instrumentation, anterior fusion with instrumentation, and various kinds of fusionless surgery.

\section{Competing interests}

The authors declare that they have no competing interests.

\section{Authors' contributions}

TM conceived of the study, participated in its design and drafted the manuscript. KT participated in the design of the study and helped to draft the manuscript. All authors read and approved the final manuscript.

\section{Acknowledgements}

We would like to thank Dr. Tomasz Kotwicki for approval to use radiographs of his patient.

\section{References}

I. Weinstein SL, Ponseti IV: Curve progression in idiopathic scoliosis. J Bone Joint Surg Am 1983, 65:447-455.

2. Edgar $M$ : The natural history of unfused scoliosis. Orthopedics | 987, I 0(6):931-939.

3. Weinstein SL, Dolan LA, Spratt KF, Peterson KK, Spoonamore MJ, Ponseti IV: Health and function of patients with untreated idiopathic scoliosis. JAMA 2003, 289:559-567.

4. Bjure J, Grimby G, Kasalicky J, Lindh M, Nachemson A: Respiratory impairment and airway closure in patients with untreated idiopathic scoliosis. Thorax 1970, 25:45 I-456.

5. Collis DK, Ponseti IV: Long-term follow-up of patients with idiopathic scoliosis not treated surgically. I Bone Joint Surg Am |969, 5 I:425-445.

6. Pehrsson K, Bake B, Larsson S, Nachemson A: Lung function in adult idiopathic scoliosis: a 20 year follow up. Thorax 1991, 46:474-478

7. Harington PR: Treatment of scoliosis. Correction and internal fixation by spine instrumentation. I Bone Joint Surg Am 1962 44:59|-610

8. Cotrel $Y$, Dubousset J, Guillaumat $M$ : New universal instrumentation in spinal surgery. Clin Orthop 1988, 227:10-23.

9. Shah SA: Derotation of the spine. Neurosurg Clin N Am 2007, I 8:339-45.

10. Suk SI, Lee SM, Chung ER, Kim JH, Kim SS: Selective thoracic fusion with segmental pedicle screw fixation in the treatment of thoracic idiopathic scoliosis: more than 5-year follow-up. Spine 2005, 30:1602-1609.

II. Asher MA, Lai SM, Burton D, Manna B, Cooper A: Safety and efficacy of Isola instrumentation and arthrodesis for adolescent idiopathic scoliosis: two- to I2-year follow-up. Spine 2004, 29:2013-2023

12. Cheng I, Kim YJ, Gupta MC, Bridwell KH, Hurford RK, Lee SS, Theerajunyaporn T, Lenke LG: Apical sublaminar wires versus pedicle screws-which provides better results for surgical correction of adolescent idiopathic scoliosis? Spine 2005, 30:2 104-2 I I 2 .

13. Winter RB, Lonstein JE, Denis F: How much correction is enough? Spine 2007, 32:264I-2643.

14. Vaughan JJ, Winter RB, Lonstein LE: Comparison of the use of spine bending and traction radiographs in the selection of the fusion area in adolescent idiopathic scoliosis. Spine 1996, 2 I:2469-2473.

15. Cheung KMC, Luk KDK: Prediction of correction of scoliosis with use of the fulcrum bendingradiograph. J Bone Joint Surg Am 1997, 79: I |44-I I50.

16. Vedantam R, Lenke LG, Bridwell KH, Linville DL: Comparison of push-prone and lateral-bending radiographs for predicting postoperative coronal alignment in thoracolumbar scoliotic curves. Spine 2000, 25:76-81.
I7. Picetti GD III, Pang D, Bueff HU: Thoracoscopic techniques for the treatment of scoliosis: early results in procedure development. Neurosurgery 2002, 5 I:978-984.

18. Sucato DJ, Kassab F, Dempsey M: Analysis of screw placement relative to the aorta and spinal canal following anterior instrumentation for thoracic idiopathic scoliosis. Spine 2004 29:554-559.

19. Maruyama T, Takeshita K, Nakamura K, Kitagawa T: Spatial relations between the vertebral body and the thoracic aorta in adolescent idiopathic scoliosis. Spine 2004, 29:2067-2069.

20. Kim YJ, Lenke LG, Bridwell KH, Kim KL, Steger-May K: Pulmonary function in adolescent idiopathic scoliosis relative to the surgical procedure. J Bone Joint Surg Am 2005, 87: I534-I54I.

21. Potter BK, Kuklo TR, Lenke LG: Radiographic outcomes of anterior spinal fusion versus posterior spinal fusion with thoracic pedicle screws for treatment of Lenke type I adolescent idiopathic scoliosis curves. Spine 2005, 30:1859-1866.

22. Hee HT, Yu ZR, Wong HK: Comparison of segmental pedicle screw instrumentation versus anterior instrumentation in adolescent idiopathic thoracolumbar and lumbar spine. Spine 2007, 32: I533- I542

23. Marks DS, lqbal MJ, Thompson AG, Piggott H: Convex spinal epiphysiodesis in the management of progressive infantile idiopathic scoliosis. Spine 1996, 2 I: | $884-1888$.

24. Betz RR, Kim J, D'Andrea LP, Mulcahey MJ, Balsara RK, Clements DH: An innovative technique of vertebral body stapling for the treatment of patients with adolescent idiopathic scoliosis: A feasibility, safety, and utility study. Spine 2003, 28:S255-265.

25. Guille JT, Betz RR, Balsara RK, Mulcahey MJ, D'Andrea LP: Clements DH: The feasibility, safety, and utility of vertebral wedge osteotomies for the fusionless treatment of paralytic scoliosis. Spine 2003, 28:S266-S274.

26. Maruyama T, Kitagawa T, Takeshita K, Seichi A, Kojima T, Nakamura $\mathrm{K}$, Kurokawa T: Fusionless surgery for scoliosis: $2-17$ year radiographic and clinical follow-up. Spine 2006, 3 I:23 I0-23 I 5.

27. Moe JH, Kharrat K, Winter RB, Cummine JL: Harington instrumentation without fusion plus external orthotic support for the treatment of difficult curvature problems in young children. Clin Orthop 1984, 185:35-45.

28. Grivas TB, Webb JK, Burwell RG: The effects of epiphysiodesis and rodding for early onset scoliosis. I Bone Joint Surg $\mathrm{Br}$ |991:32-33.

29. Akbarnia BA, Marks DS, Boachie-Adjei O, Thompson AG, Asher MA: Dual growing rod technique for the treatment of progressive early-onset scoliosis. Spine 2005, 30:546-557.

30. Campbell RM, Smith MD, Mayes TC, Mangos JA, Willey-Courand DB, Kose N, Pinero RF, Alder ME, Duong HL, Surber JL: The effect of opening wedge thoracostomy on thoracic insufficiency syndrome associated with fused ribs and congenital scoliosis. Bone Joint Surg Am 2004, 86: I659-1674.

Publish with Bio Med Central and every scientist can read your work free of charge

"BioMed Central will be the most significant development for disseminating the results of biomedical research in our lifetime. "

Sir Paul Nurse, Cancer Research UK

Your research papers will be:

- available free of charge to the entire biomedical community

- peer reviewed and published immediately upon acceptance

- cited in PubMed and archived on PubMed Central

- yours - you keep the copyright
BioMedcentral 